\title{
Effective Teaching Methods and Proposed Web Libraries for Designing Animated Course Content: A Review
}

\author{
Rajesh Kumar Kaushal \\ Department of Computer Applications \\ Chitkara University, CU \\ Rajpura, India
}

\author{
Dr. Surya Narayan Panda \\ Chitkara University Research and Innovation Network \\ Chitkara University, CU \\ Rajpura, India
}

\begin{abstract}
The primary aim of education system is to improve cognitive and computational skills in students. It cannot be achieved by just using the latest technology. This goal can only be achieved through effective teaching methods in combination with effective technology. Lot of researchers have offered effective teaching methods and published their findings in the past. Most of them offered teaching through animations, puzzles, games and storyline. This research paper focuses on identifying effective teaching methods offered by researchers and their findings by reviewing last few years articles published in renowned journals and conferences. Another aim of this paper is to propose ideas to make teaching tools more effective that can help students to understand difficult concepts deeply, improve cognitive and computational skills and retain knowledge for longer times. These ideas will serve as future research directions in this area. Another aim of this research paper is to introduce latest web libraries that can help educators to design animated courses.
\end{abstract}

Keywords-cognitive; web education; dynamic teaching tool; animation libraries

\section{INTRODUCTION}

The traditional way of teaching was class-room learning which involves face to face teacher student interaction, learning through books, studying through teachers notes and appearing for final examination to obtain scores as high as possible. In traditional learning there was minor involvement of audio and video aids. The entire focus was on reading text. Presently teaching aids has changed revolutionary. In present era, educational aids involve traditional teaching style with addition to extensive use of audio and video aids. It all happens due to rapid growth of technology and its availability at low cost. The evolvement of audio video aids helps students to understand concepts better than earlier. But this teaching technology is less effective to improve cognitive and computational skills in students. One possible solution to this issue is that more time and efforts should be devoted in designing effective teaching methods rather than technology itself. Effective teaching methods and effective technology only can help students to learn deeply with higher engagement. Several teaching institutions and researchers has offered effective teaching methods that focuses on teaching through animations, by solving subject related puzzles, by playing games, quiz and by storyline. To achieve this they first redesigned the course into visual components (animations, puzzles, games etc.) and then offered it through web platform, mobile platforms and through offline applications. This research paper focuses on identifying effective teaching methods offered by researchers and their findings by reviewing last few year articles published in renowned journals. Another aim of this paper is to propose ideas to make teaching more effective that can help students to understand difficult concepts deeply, improve cognitive and computational skills and retain knowledge for longer times.

This paper first review relevant literature that depicts what efforts researchers have already made in the past to obtain better teaching results by using interactive teaching methods. Thereafter it discusses identified research problems and then this article will propose some useful web libraries to make interactive and dynamic web animations. At last article will close the discussion by suggesting future directions.

\section{EFFECTIVE TEACHING Methods AND FINDINGS BASED ON PUBLISHED ARTICLES}

In September 2011, Antonis, Daradoumis, Papadakis and Simos presented an evaluation methodological framework that could assess the learning methodology used [8]. It could also assess some of the educational and technical issues involved, and the solutions chosen to provide an easier to use learning environment to enhance the learning experience. In this article methodological framework was offered for the evaluation of distance learning. The entire focus was on three main evaluation parameters listed below [8]:

1) Information and support should be provided to learner not only at the beginning but also during studies.

2) To evaluate learner's performance (final exam and continuous evaluation).

3) To evaluate learner's satisfaction (Enjoyment, Compensation, Benefits, Content)

The course content was offered using animations, presentations and audio/video files that were uploaded on LAMS (Learning Activity Management System) and this framework also emphasis on student-teacher interaction for success. The LAMS tool was a popular learning system allowing authoring, monitoring and sharing. Researcher obtained positive satisfactory results in all research questions. To obtain results pre-questionnaire, post-questionnaire and final result analysis was used. In Fig. 1 we are showing results of end-term questionnaire only. 
TABLE I. OBJECTIVES \& CORRESPONDING RESULTS [8]

\begin{tabular}{|c|c|c|}
\hline \multicolumn{3}{|c|}{ Results (End-Term Questionnaire) } \\
\hline $\begin{array}{c}\text { Questionnaire } \\
\text { Type }\end{array}$ & $\begin{array}{c}\text { Evaluation } \\
\text { Framework Axis }\end{array}$ & Results \\
\hline End-Term & $\begin{array}{c}\text { Information \& } \\
\text { support provided to } \\
\text { learners }\end{array}$ & $\begin{array}{l}\text { In a nutshell } 55 \% \text { students } \\
\text { were very satisfied and } \\
5 \% \text { students felt } \\
\text { disappointed. }\end{array}$ \\
\hline End-Term & $\begin{array}{l}\text { Learner's } \\
\text { Performance }\end{array}$ & $\begin{array}{l}75 \% \text { students believed } \\
\text { that their overall } \\
\text { performance improved } \\
\text { and } 25 \% \text { students believed } \\
\text { that either they should put } \\
\text { more efforts or in other } \\
\text { words they were not } \\
\text { satisfied with their overall } \\
\text { performance. }\end{array}$ \\
\hline End-Term & $\begin{array}{l}\text { Learner's } \\
\text { Satisfaction }\end{array}$ & $\begin{array}{l}\text { It is divided into several } \\
\text { aspects like enjoyment, } \\
\text { compensation, benefits, } \\
\text { suitability of content, } \\
\text { adequacy, applicability } \\
\text { etc. and researcher got } \\
\text { significant positive results } \\
\text { in every aspect like } 76 \% \\
\text { students enjoyed the } \\
\text { course and } 90 \% \text { of } \\
\text { students believed that } \\
\text { material was adequate. }\end{array}$ \\
\hline
\end{tabular}

In 2011, Williams \& Dugan claimed that presenting course material according to student's preferences and pace can help students to understand subject more effectively [6]. Even though there were three main objectives of the study but two of them were major as listed below:

1) Online Learning using GOAL can be as effective as classroom learning.

2) Adapting the presentation style to the preferred learning style of the student will enhance the student's learning experience.

To achieve above objectives researcher offered a project named GOAL (Guided on Demand Adaptive Learning) [6]. It allowed students to set the course pace and provides additional details/explanations whenever needed. The study was conducted on the subject named "Digital Logic Design". The course was designed into various activities like animated gates or circuits, puzzles and problems. Three topics were targeted namely Boolean algebra, sequential systems and addition. To evaluate the effectiveness of this approach, researcher collected data of three semesters and found that GOAL approach could achieve learning in less time as compared to class-room learning. According to the results shown in the article, average time to teach sequential system in classroom in spring 2010, fall 2010 and spring 2011 were 62.2, 50 and 67 minutes respectively. After teaching with GOAL average time required was $28.4,19.3$ and 25.8 respectively. The same effect was observed in rest of the topics also.

In December 2012, Hwang, Wu and Chen suggested that learning achievements and flow-experience could be enhanced by playing games and by web based problem solving [1]. In this research article the objectives were to study impact of online game approach on students learning, students flow experience and learning attitudes towards science learning. To find answers to these research questions they did an experimental study on 50 elementary school students who participated voluntarily. The study was conducted on butterfly ecology subject. Students were divided into two group's namely experimental group and control group. Experimental group studied through web based contents and control group studied through learning sheets and keyword search on internet. A board game was designed for experimental study. Students could move to the next location on board after throwing dice. On moving to each board location an activity triggered up and students had to solve it to move further. If the student failed to solve activity/problem a second time, learning system would show the correct answer. The game finished after solving all problems. Researcher got results through pretest and pre-test questionnaire and post-test and post-test questionnaire. Mean score of experimental group was much higher than control group in learning achievements. T-test result for flow experiences and learning attitudes was also significant. The researchers, at the end of this study claimed that it might be difficult to claim that all of the findings are significant since the numbers of participants were not large and the activity period was short.

In January 2012, Rutten, van Joolingen and van der Veen tried to find the effect of simulation conditions on learning process [9]. To accomplish this task they didn't conduct any experimental study rather they reviewed relevant published articles from databases like ERIC, SCOPUS and ISI Web of Knowledge. Articles between 2001 and 2010 were reviewed. Final results were in favor of simulation conditions. The analysis also showed that simulation conditions were best applicable on laboratory usages.

In 2012, Jalal Kawash offered different teaching methodology. The study was conducted on first year computer science students. The idea was to improve learning by problem solving in combination with puzzle-based environment [12]. They targeted topics like basic set theory, graphs and trees, computer organization, databases fundamentals and programming concepts. Activities were designed like puzzles to improve critical thinking. At the end a survey was conducted to know the effectiveness of teaching mechanism through puzzle based along with problem solving. The results showed that majority of participants agreed that this approach is useful but offering the same course methodology second time gained better responses [12].

In 2013, Combefis, den SCHRIECK and Nootens designed a web platform developing algorithm design skills and they named this platform as ILPADS (Interactive Learning of Programming and Algorithm Design Skills). The website aimed to serve as working material to support teachers for their computer science courses in secondary schools [3]. They targeted students having age group 12 to 18 . Every activity was decomposed into three different stages. In first stage learners were confronted to an interactive animation. It enabled them to discover algorithm and built it in their mind. In the second stage they were supposed to concretize the algorithm that they already had in their mind. They did it with an executable flowchart that could run on an instance of the problem. In the third stage learners were supposed to write code representing their algorithm. The entire ILPADS platform was designed in 
HTML5, CANVAS and JavaScript. At the time of publication of this article no experimental study was conducted.

In 2013, O’Donovan, Gain \& Marais suggested that well designed game based course content could increase engagement and encourage targeted behaviors among users [5]. In this research paper one of the university course names "Computer Games Development" was offered using gamification using online learning management tool named VULA. Objectives of their study are listed below [5]:

1) Increase student engagement and motivation.

2) Improve lecture attendance and in-class participation.

3) Enhance content understanding and problem solving skills.

Results were measured using marks obtained in the course, lecture evaluations, total lectures attended by students and questionnaire. This article mainly emphasis on few design principles that should be kept in mind while designing games and to obtain good results.

1) Game should have special meaning for the user.

2) Game should be inspiring so that students feel motivated to master the topic.

3) Game should be autonomous (freedom of choice).

4) Game should have sense of discovery and visually pleasant.

5) Game approach should involve reward system like winning points, stars and badges.

A questionnaire was distributed at the end of course to know students views on subject understanding, engagement and course marks. The results are shown below:

TABLE II. IMPROVED UNDERSTANDING [5]

\begin{tabular}{|c|c|c|c|c|c|c|}
\hline & & Results (C & uestionna & Based) & & \\
\hline Improved & Understar & ling & & & & \\
\hline $\begin{array}{l}\text { Strongly } \\
\text { Disagree }\end{array}$ & Disagree & Neutral & Agree & $\begin{array}{c}\text { Strongly } \\
\text { Agree }\end{array}$ & mean & Std Dev \\
\hline 0 & 4 & 5 & 15 & 10 & 3,91 & 0,97 \\
\hline Improvec & Engageme & & & & & \\
\hline $\begin{array}{l}\text { Strongly } \\
\text { Disagree }\end{array}$ & Disagree & Neutral & Agree & $\begin{array}{c}\text { Strongly } \\
\text { Agree }\end{array}$ & mean & Std Dev \\
\hline 0 & 2 & 2 & 13 & 17 & 4,32 & 0,84 \\
\hline Higher $\mathrm{N}$ & rks & & & & & \\
\hline $\begin{array}{l}\text { Strongly } \\
\text { Disagree }\end{array}$ & Disagree & Neutral & Agree & $\begin{array}{c}\text { Strongly } \\
\text { Agree }\end{array}$ & mean & Std Dev \\
\hline 1 & 1 & 11 & 15 & 6 & 3,71 & 0,91 \\
\hline Improved & by Story a & d Theme & & & & \\
\hline $\begin{array}{l}\text { Strongly } \\
\text { Disagree }\end{array}$ & Disagree & Neutral & Agree & $\begin{array}{c}\text { Strongly } \\
\text { Agree }\end{array}$ & mean & Std Dev \\
\hline 1 & 2 & 11 & 16 & 4 & 3,59 & 0,89 \\
\hline
\end{tabular}

The same course were also taught in 2011 and that time mean score was $70.8 \%$ with standard deviation of 10.3 but after offering the same course in 2012 with gamification the results were much better. In 2012 mean score was $74.9 \%$ with standard deviation of 8.6. The researcher also got positive significant results in average attendance which was $79.1 \%$ and was much higher than attendance in other computer science courses.

In January 2014, Brazilai and Blau did an experimental study to find the impact of scaffolding game based learning on learning achievements, perceived learning and game experiences [2]. In this research article the objectives were to study impact of game based learning with addition to external scaffolding on learner's ability, perception of learning, flow and enjoyment in the game. Another objective was to find correlation between learning achievements, perceived learning, flow and enjoyment. To conduct the study they used "My Money" website that includes set of online games and study materials that helped students to develop financial and mathematical skills. The study was conducted on elementary school students with average age group of 8-12 years. Participants were divided into three groups. One group would only play the game and this group was named as "Play only". Second group would study first (scaffolding) and then play the game. This group was named as "Study and Play". Third group would play first and then study (external scaffolding). This group was named as "Play and Study". The results are shown in Fig.3.

TABLE III. IMPACT ON FORMAL LEARNING ACHIEVEMNT [2]

\begin{tabular}{|l|c|c|c|c|}
\hline \multicolumn{4}{|c|}{ Pre-Game and Post-Game Solving Results: Learning Achievement } \\
\hline \multicolumn{1}{|c|}{ Conditions } & \multicolumn{2}{|c|}{ Pre-game score } & \multicolumn{2}{c|}{ Post-game score } \\
\hline Play Only & $\boldsymbol{M}$ & $\boldsymbol{S D}$ & $\boldsymbol{M}$ & $\boldsymbol{S D}$ \\
\hline \multirow{2}{*}{ Study and Play } & 2.62 & 1.87 & 2.58 & 1.89 \\
\hline Play and Study & 2.72 & 2.03 & 3.47 & 1.98 \\
\hline
\end{tabular}

In second condition "Studying First (external scaffolding) and then play" got better post results.

TABLE IV. IMPACT ON FORMAL LEARNING ACHIEVEMNT [2]

\begin{tabular}{|l|c|c|c|c|c|c|}
\hline \multicolumn{7}{|c|}{ Pre-Game and Post-Game Solving Results: Perceived Learning, Flow, } \\
Enjoyment
\end{tabular}

Adding the external scaffold before the game lowered learner's perceptions of how much they had learned from the game. 
TABLE V. RELATIONSHIP BETWEEN LEARNING ACHIEVEMENT, PERCEIVED LEARNING , FLOW AND ENJOYMENT [2]

\begin{tabular}{|l|c|c|c|c|}
\hline \multicolumn{5}{|c|}{$\begin{array}{c}\text { Correlation between problem solving assessment, perceived learning } \\
\text { and enjoyment }\end{array}$} \\
\hline \multicolumn{1}{|c|}{ Variable } & $\mathbf{1}$ & $\mathbf{2}$ & $\mathbf{3}$ & $\mathbf{4}$ \\
\hline $\begin{array}{l}\text { Problem Solving } \\
\text { Assesment }\end{array}$ & - & -.11 & -.01 & -.05 \\
\hline Perceuved Learning & & - & $.61^{* * *}$ & $.50^{* * *}$ \\
\hline Flow & & & - & $.73^{* * *}$ \\
\hline Enjoyment & & & & - \\
\hline
\end{tabular}

The table shows positive correlation between perceived learning and flow, perceived learning and enjoyment and between flow and enjoyment.

In 2014 researchers like Lee, Bahmani, Kwan, Laferte, Charters, Horvath and Fanny luor et al. worked on seven principles listed below to see their influence on novice programmers [4].

1) Debugging first

2) Game-oriented

3) Fallible goals

4) Instruction

5) Scaffold

6) Help

7) Gender inclusiveness

They presented a principled approach to teach programming using a debugging game called GIDGET, which was created using a unique set of seven design principles. The experimental study was conducted during the summer camp with a median age of 13.5 years. The primary purpose of this work was to find answers to the following research question [4].

"How does these seven principles influence the ways novice programmer learn programming concepts and solve programming problem"

Researcher tried to find answers to above stated objective by studying various barriers [4]. The article showed noticeable improvement in algorithm design barriers (19\%) v/s learning phase barriers $(51 \%)$. Two of the learning phase barriers improved by nearly $90 \%$ compared to the best algorithm design barrier improvement of $41 \%$. Total 15 teams improved on learning phase barriers and on the other hand only 10 teams improved on algorithm design barriers. Teams especially struggled with composition barriers, encountering them frequently but demonstrating only $7 \%$ improvement - the least amount of improvement out of all barrier types. One interesting fact was that the algorithm design barrier did not greatly improve with instruction and practice. Algorithm design concepts needed more thorough explanations and help. Similar improvement was observed in both males (64\%) and females $(58 \%)$ which seemed to be encouraging [4].

In 2014, Edgcomb \& Vahid stated that interactive web content like animations, responsive questions and interactive exercises can enhance students learning as compared to static text and drawings written in electronic textbooks [7]. The study was conducted on $\mathrm{C}++$ programming. The primary objective of the study was "To compare the lesson effectiveness of electronic textbooks having static content versus interactive web native content". The researcher got positive significant results in all areas. Results are shown in Fig.6.

TABLE VI. PRE-LESSON Results [7]

\begin{tabular}{|l|c|}
\hline \multicolumn{2}{|c|}{ Pre-Lesson Result Based on Content Type } \\
\hline Content Type & $\begin{array}{c}\text { AVG Pre-Lesson Correct } \\
\text { Answers }\end{array}$ \\
\hline Static Web Content & 1.8 \\
\hline Interactive Web Content & 2.2 \\
\hline
\end{tabular}

TABLE VII. POST-Lesson Results [7]

\begin{tabular}{|l|c|}
\hline \multicolumn{2}{|c|}{ Post-Lesson Result Based on Content Type } \\
\hline Content Type & $\begin{array}{c}\text { AVG Post-Lesson } \\
\text { Correct Answers }\end{array}$ \\
\hline Static Web Content & 7.3 \\
\hline Interactive Web Content & 8.6 \\
\hline
\end{tabular}

All those participants who were assigned interactive web content improved $16 \%$ more than static web content. Participants spent average time of 17.5 minutes while using interactive web content and 9.4 minutes while using static web content [7].

In 2014, Costa, Toda, Mesquita and Brancher stated that learning through interactive games has shown positive results in many areas like marketing, education and health and now educators are introducing this concept in IT courses [10]. They focused on developing DSLEP (Data Structure Learning Platform) to aid higher education IT courses. The idea was to create activities that help students to enhance their understanding of various data structures concepts. DSLEP targeted major data structures concept like stack, queue, list, tree, search, graphs and hashing. One animated activity is designed for each concept using HTML 5 support. All activities were also offered on mobile devices for mobility purpose. Researcher also showed interest to conduct experimental study to see the effect of such tool on students understanding in future.

\section{IDENTIFIED RESEARCH PROBLEMS}

After reviewing literature it is found that animations used for teaching should not be static in nature rather teaching tools should offer concept like animation on demand so that students can deeply interact with tool as no one would like to learn through same animation demonstrating particular topic using same data set every-time. The learner should ask teaching tool to demonstrate a particular concept through animation by providing his/her choice of data set. The teaching tool should be smart enough to produce animation instantly. It can only happen through intelligent web scripting algorithm working behind the tool. Secondly to obtain accurate results, experimental study should be conducted in a long time span covering entire syllabus of particular stream. Moreover, every topic of entire syllabus should be taught using at-least two different styles (animations, puzzles, storyline, and games etc.). 


\section{PRoposed Web LIBRARIES TO MAKE ANIMATED COURSE CONTENT}

There are several libraries that can be used to make animations. JavaScript is the most popular language available on web and it can be used for animation also. JavaScript can be fully utilized when used with HTML5 CANVAS. HTML5 CANVAS is especially introduced for making animations, web games and many more. JavaScript is difficult to handle when code becomes too large. So the alternate is using jCanvas which is built upon jQuery framework [11]. jCanvas can interact with HTML5 CANVAS and project is even easier to handle even if the code becomes too large. One another important aspect of jCanvas is that it works on layers, which is a very useful feature to make dynamic web animations. One another alternate is VELOCITY JavaScript library. It has large set of inbuilt functions to deal with animations.

\section{FUTURE DIRECTIONS}

After reviewing articles it has been observed that dynamic web based tool is required to teach students to enhance their subject specific knowledge. The proposed simulator won't teach through fixed or static examples. Rather it can generate random data set and based on that it can produce new animation instantly and thus teaching same concept through endless examples. This kind of tool is feasible for practical subjects rather than pure theoretical subjects. Moreover, it has also been observed that while teaching courses through web animations, effort should be made to redesign entire course into animated form for better results. We should also like to suggest that each topic should be offered using at least two different approaches (e.g. teaching a topic through introductory animation and then through puzzle or teaching through interactive game or through storyline) wherever possible to obtain better results. Moreover teaching tool can be deployed on client/server architecture to reach maximum audience.

\section{REFERENCES}

[1] Hwang, G. J., Wu, P. H., \& Chen, C. C. (2012). An online game approach for improving students' learning performance in web-based problem-solving activities. Computers \& Education, 59(4), 1246-1256.

[2] Barzilai, S., \& Blau, I. (2014). Scaffolding game-based learning: Impact on learning achievements, perceived learning, and game experiences. Computers \& Education, 70, 65-79.

[3] Combéfis, S., den SCHRIECK, V. V., \& Nootens, A. (2013). Growing Algorithmic Thinking Through Interactive Problems to Encourage Learning Programming. Olympiads in Informatics, 7, 3-13.

[4] Lee, M. J., Bahmani, F., Kwan, I., LaFerte, J., Charters, P., Horvath, A., ... \& Ko, A. J. (2014, July). Principles of a debugging-first puzzle game for computing education. In Visual Languages and Human-Centric Computing (VL/HCC), 2014 IEEE Symposium on (pp. 57-64). IEEE.

[5] O'Donovan, S., Gain, J., \& Marais, P. (2013, October). A case study in the gamification of a university-level games development course. In Proceedings of the South African Institute for Computer Scientists and Information Technologists Conference (pp. 242-251). ACM.

[6] Williams, R. D., \& Dugan, J. B. (2011, October). Improving efficiency in engineering education through asynchronous computer-based instruction. InFrontiers in Education Conference (FIE), 2011 (pp. T4C1). IEEE

[7] Edgcomb, A., \& Vahid, F. (2014). Effectiveness of Online Textbooks vs. Interactive Web-Native Content. In Proc. of 2001 ASEE Annual Conf. and Exposition.

[8] Antonis, K., Daradoumis, T., Papadakis, S., \& Simos, C. (2011). Evaluation of the effectiveness of a web-based learning design for adult computer science courses. Education, IEEE Transactions on, 54(3), 374380.

[9] Rutten, N., van Joolingen, W. R., \& van der Veen, J. T. (2012). The learning effects of computer simulations in science education. Computers \& Education,58(1), 136-153.

[10] Costa, E. B., Toda, A. M., Mesquita, M. A., \& Brancher, J. D. DSLEP (Data Structure Learning Platform to aid in Higher Education IT Courses).

[11] http://projects.calebevans.me/jcanvas/.

[12] Kawash, Jalal. "Engaging students by intertwining puzzle-based and problem-based learning." Proceedings of the 13th annual conference on Information technology education. ACM, 2012. 